\title{
Nitric Oxide-induced Protein S-nitrosylation Causes Mitochondrial Dysfunction and Accelerates Post-ovulatory Aging of Oocytes in Cattle
}

\author{
Ying-Jie Niu ${ }^{1}$, Dongjie Zhou ${ }^{1}$, Wenjun Zhou ${ }^{1}$, Zheng-Wen $\mathrm{Nie}^{1}$, Ju-Yeon Kim ${ }^{1}$, YoungJin $\mathrm{Oh}^{2}$, \\ So-Rim Lee ${ }^{2}$ and Xiang-Shun $\mathrm{Cui}^{1, *}$ \\ ${ }^{1}$ Department of Animal Science, Chungbuk National University, Cheongju 28644, Korea \\ ${ }^{2}$ Chung Cheong Buk-Do Institute of Livestock and Veterinary Research, Cheongju 28153, Korea
}

Received March 17, 2020

Revised March 23, 2020

Accepted March 24, 2020

*Correspondence

Xiang-Shun Cui

E-mail: xscui@cbnu.ac.kr

ORCID

https://orcid.org/0000-0001-6180-6401

\begin{abstract}
Nitric oxide (NO)-induced protein S-nitrosylation triggers mitochondrial dysfunction and was related to cell senescence. However, the exact mechanism of these damages is not clear. In the present study, to investigate the relationship between in vitro aging and NO-induced protein S-nitrosylation, oocytes were treated with sodium nitroprusside dihydrate (SNP), and the resultant S-nitrosylated proteins were detected through biotin-switch assay. The results showed that levels of protein S-nitroso thiols (SNO)s and expression of S-nitrosoglutathione reductase (GSNOR) increased, while activity and function of mitochondria were impaired during oocyte aging. Addition of SNP, a NO donor, to the oocyte culture led to accelerated oocyte aging, increased mitochondrial dysfunction and damage, apoptosis, ATP deficiency, and enhanced ROS production. These results suggested that the increased NO signal during oocyte aging in vitro, accelerated oocyte degradation due to increased protein S-nitrosylation, and ROS-related redox signaling.
\end{abstract}

Keywords: cattle, mitochondria, nitric oxide, post-ovulatory aging, S-nitrosylation

\section{INTRODUCTION}

During S-nitrosylation, covalent addition of nitric oxide group (-NO) to the thiol side chain of cysteine in protein forms S-nitroso thiol (SNO) (Hess and Stamler, 2012). Controlled S-nitrosylation regulates activities and functions of several proteins (Jaffrey et al., 2001), while dysregulated S-nitrosylation is involved in pathophysiology, including cellular senescence and cell death (Nakamura and Lipton, 2011; Iyer et al., 2014). Steady-state concentrations of protein SNO (PSNO) depend on the balance of S-nitrosylation and denitrosylation. Nitric oxide synthase (NOS) catalyzes the production of NO, and nitrosylases directly transfer NO group to protein (Seth et al., 2018), while denitrosylases induce the S-denitrosylation through the enzyme S-nitrosoglutathione reductase (GSNOR).

Previous studies have reported that NO-induced protein S-nitrosylation triggers mitochondrial fragmentation and dysfunction, accumulation of damaged mitochondria, endoplasmic reticulum stress, and protein misfolding, causing bioenergetic compromise (Hess and Stamler, 2012; Raju et al., 2015). GSNOR decreases excessive protein Snitrosylation in primary cells undergoing senescence, as well as in mice and human cells during their life span (Rizza et al., 2018). GSNOR deficiency promotes mitochondrial nitrosative stress, leading to excessive S-nitro- 
Niu et al. Protein S-nitrosylation Induce Mitochondrial Dysfuction

sylation of dynamin-related protein 1 (Drp1) and Parkin, the two components involved in mitochondrial fission and clearance, thereby impairing mitochondrial quality control system.

After maturation, the oocytes are arrested in metaphase II (MII) till fertilization in the oviduct or in culture medium. Unless fertilized within the optimal time, MII oocytes undergo degradative process called post-ovulatory aging (Lord and Aitken, 2013). This is not the same as the oocyte aging through the aging of the mother. During the production of transgenic animals and assisted reproduction of humans, the in vitro maturation time of oocytes is often prolonged due to unavoidable reasons. As a result, oocytes undergo aging process. Post-ovulatory aging adversely affects various cellular structures, including cortical granules (Ducibella et al., 1990; Xu et al., 1997), zona pellucida (Dodson et al., 1989; Xu et al., 1997), maturation-promoting factor (MPF) and MAPK levels (Kikuchi et al., 2002), cytoskeleton, and chromosomes (Wakayama et al., 2004).

A previous study reported that nitric oxide (NO) signals mediate the aging of oocytes (Premkumar and Chaube, 2015). However, very limited research has focused on the effect of NO-related redox signaling on oocyte quality during oocyte aging. Another report shows that NO-related redox signaling is involved in S-nitrosylation of proteins, affecting morphology and function of mitochondria, releasing calcium stored in the endoplasmic reticulum, regulating cellular autophagy and apoptosis (Sun et al., 2007), and is closely related to ROS-related redox signaling. Therefore, exploring the changes and mechanisms of NO-related redox signaling during oocyte aging is important for delaying, if not prevention of oocyte aging.

\section{MATERIALS AND METHODS}

Unless otherwise indicated, all chemicals were purchased from Sigma-Aldrich Co., Inc. (St. Louis, MO, USA) and all experimental manipulations were performed on a heated stage, maintained at $38.5^{\circ} \mathrm{C}$.

\section{Collection and in vitro maturation of cattle oocytes}

All experimental protocols were carried out in accordance with the guidelines of the Institutional Animal Care and Use Committee of the Chungbuk National University Laboratory Animal Center, Cheongju, South Korea.
Ovaries from Hanwoo cattle were collected from a local slaughterhouse, and transported in saline at $38.5^{\circ} \mathrm{C}$ to the laboratory. In vitro oocyte maturation was performed as previously described (Hwang et al., 2016; Choudhury et al., 2017; Hassan et al., 2017; Choi et al., 2019; Jeon et al., 2019). Cumulus oocyte complexes were aspirated from the follicles using a syringe, washed three times in Tyrode's lactate-4-(2-hydroxyethyl)-1-piperazineethanesulfonic acid, and cultured in tissue culture medium 199 (TCM 199) supplemented with $10 \%$ fetal calf serum (10082-147; Gibco, USA), $1 \mu \mathrm{g} / \mathrm{mL} \beta$-estradiol (E2758; Sigma, USA), $10 \mu \mathrm{g} /$ $\mathrm{mL}$ follicle-stimulating hormone (F2293; Sigma), $10 \mathrm{ng} / \mathrm{mL}$ epidermal growth factor (E4127; Sigma), $100 \mathrm{IU} / \mathrm{mL}$ penicillin/streptomycin, $22 \mu \mathrm{g} / \mathrm{mL}$ sodium pyruvate (P5280; Sigma), and $95 \mu \mathrm{g} / \mathrm{mL}$ L-cysteine (C7352; Sigma) at $38.5^{\circ} \mathrm{C}$ in a humidified atmosphere with $5 \% \mathrm{CO}_{2}$ and $95 \%$ air.

\section{In vitro aging and SNP treatment}

After removing cumulus cells by repeated pipetting in $1 \mathrm{mg} / \mathrm{mL}$ hyaluronidase, only the oocytes with first polar bodies were used for the present studies. For post-ovulatory oocyte aging, the collected oocytes at metaphase II (MII) were cultured in fresh in vitro maturation medium (IVM) covered with mineral oil, for 24 or $48 \mathrm{~h}$ at $38.5^{\circ} \mathrm{C}$ in humidified atmosphere $\left(5 \% \mathrm{CO}_{2}\right)$. SNP was dissolved in DMSO to prepare $200 \mathrm{mM}$ stock solutions. To determine whether NO-induced protein S-nitrosylation was harmful during oocyte aging process, MII oocytes were cultured in fresh IVM with or without $160 \mu \mathrm{M}$ SNP.

\section{Biotin-switchd assay for detection of S-nitrosylated proteins}

The biotin-switch method for detecting S-nitrosylated proteins was used as described previously (Haun et al., 2013; Lee et al., 2013). In brief, oocytes from the different experimental groups were fixed in $3.7 \%$ paraformaldehyde at room temperature overnight, washed three times with HEN (250 mM HEPES, pH 7.7, 1 mM EDTA, $0.1 \mathrm{mM}$ neocuproine) containing $0.1 \%$ Triton $\mathrm{X}-100$ for 5 min. Thiol groups were then blocked with $20 \mathrm{mM}$ methyl methane thiosulphonate (MMTS), a thiol-reactive agent in the same buffer at $4^{\circ} \mathrm{C}$ for $30 \mathrm{~min}$. The oocytes were then washed three times with HEN, and incubated with $1 \mathrm{mM}$ ascorbate to reduce the S-nitrosothiols and with $0.4 \mathrm{mM}$ MTSEA-Texas Red, a fluorescent derivative of MTSEA in HEN at room temperature for $1 \mathrm{~h}$. Excess dye was removed 
by repeated washing of the oocytes with HEN containing $0.1 \%$ Triton X-100. Stained oocytes were then mounted on glass slides in prolonged antifade mounting medium.

\section{ROS measurements}

Total ROS levels in oocytes were determined using 2', $7^{\prime}$-dichlorodihydrofluorescein diacetate $\left(\mathrm{H}_{2} \mathrm{DCF}-\mathrm{DA}\right.$, Cat \# D399, Molecular Probes, USA) as previously described (Nasr-Esfahani et al., 1990; Park et al., 2017; Fang et al., 2018; Jeon et al., 2019). Briefly, oocytes were incubated for $15 \mathrm{~min}$ in PBS/PVA containing $10 \mu \mathrm{M} \mathrm{H}_{2} \mathrm{DCF}-\mathrm{DA}$ at $38.5^{\circ} \mathrm{C}$, and washed three times with PBS/PVA. Fluorescence signals were captured using a digital camera (DP72; Olympus, Tokyo, Japan) connected to a fluorescence microscope (IX70, Olympus). Total ROS levels were quantified by analyzing the fluorescence intensity of the oocytes using Image J version 1.44g software (National Institutes of Health, Bethesda, MD, USA).

\section{Total and active mitochondrial staining}

Oocytes were incubated with $500 \mathrm{nM}$ MitoTracker Red CMXRos (Cat \# M7512, Invitrogen) at $38.5^{\circ} \mathrm{C}$ for $30 \mathrm{~min}$. After three washes with PZM-5 medium, TOM20 staining was carried out as described in the Immunofluorescence and confocal microscopy subsection. After this, the oocytes were stained with $10 \mu \mathrm{g} / \mathrm{mL}$ Hoechst 33342 for $10 \mathrm{~min}$, washed three times with PBS/PVA, mounted on slides, and examined under a confocal microscope (Zeiss LSM 710 META). Images were processed using Zen software (version 8.0, Zeiss). The fluorescence intensity of TOM20 and MitoTracker Red was detected by Image $\mathrm{J}$ version $1.44 \mathrm{~g}$ software (National Institutes of Health, Bethesda, MD, USA).

\section{Immunofluorescence and confocal microscopy}

Immunostaining was performed as previously reported (Kim et al., 2019). After washing three times with PBS/ PVA, oocytes were fixed in $3.7 \%$ paraformaldehyde at room temperature for $30 \mathrm{~min}$, permeabilized with $0.5 \%$ Triton X-100 at room temperature for $30 \mathrm{~min}$ and incubated in $1.0 \%$ BSA at room temperature for $1 \mathrm{~h}$. These oocytes were then incubated overnight at $4^{\circ} \mathrm{C}$ with either anti-Caspase 3, anti-GSNOR or anti-TOM20 antibodies, diluted in blocking solution. After washing three times with PBS/PVA, the oocytes were incubated at room temperature for $1 \mathrm{~h}$ with Alexa Fluor $488^{\mathrm{TM}}$ Donkey anti-
Mouse IgG $(\mathrm{H}+\mathrm{L})(1: 200$; Cat \# A21202, Invitrogen), or Alexa Fluor $546^{\mathrm{TM}}$ Donkey anti-Rabbit IgG (H + L) (1:200; Cat \# A10040, Invitrogen). After this, the oocytes were stained with $10 \mu \mathrm{g} / \mathrm{mL}$ Hoechst 33342 for $10 \mathrm{~min}$, washed three times with PBS/PVA, mounted on slides, and examined under a confocal microscope (Zeiss LSM 710 META). Images were processed using Zen software (version 8.0, Zeiss).

\section{Analysis of MtDNA copy number}

Each pool of 10 oocytes was transferred to a $0.2 \mathrm{~mL}$ tube containing $8 \mu \mathrm{L}$ lysis buffer $(20 \mathrm{mM}$ TrisCl, $0.4 \mathrm{mg} /$ $\mathrm{mL}$ proteinase $\mathrm{K}, 0.9 \% \mathrm{NP}-40$, and $0.9 \%$ Tween 20 ) and heated for $30 \mathrm{~min}$ at $65^{\circ} \mathrm{C}$, and for $5 \mathrm{~min}$ at $95^{\circ} \mathrm{C}$. Samples were diluted 1:25 in sterile $\mathrm{ddH}_{2} \mathrm{O}$ before analysis. Subsequently, real-time quantitative PCR was performed by using WizPure ${ }^{\mathrm{TM}}$ qPCR Master (Super Green) mix (Cat \# W1731-8, Wizbiosolution, Seongnam, South Korea) (Jeon et al., 2019; Lee et al., 2019a; Lee et al., 2019b). Amplification was conducted as follows: $95^{\circ} \mathrm{C}$ for $3 \mathrm{~min}$, followed by 40 cycles of $95^{\circ} \mathrm{C}$ for $15 \mathrm{~s}, 60^{\circ} \mathrm{C}$ for $25 \mathrm{~s}$, and $72^{\circ} \mathrm{C}$ for $10 \mathrm{~s}$, with a final extension at $72^{\circ} \mathrm{C}$ for $5 \mathrm{~min}$. The target genes were ND1 (Forward primer: GAACCACTACGACCCGCTAC, Reverse primer: ACGGCTAGGCTTGATATGGC). Relative quantification method was used for calculation of mtDNA copy number.

\section{ATP measurements}

ATP content was measured using luciferin-luciferase ATP assay in luminometer (CentroPRO LB 962; Berthold, ND, USA) according to the instructions of the manufacturer of the ATP determination kit (A22066, Molecular Probes). Briefly, 10 oocytes were collected in a $0.2 \mathrm{~mL}$ centrifuge tube containing $20 \mu \mathrm{L}$ of lysis buffer $(20 \mathrm{mM}$ TrisCl, 0.9\% Nonidet- 40 , and $0.9 \%$ Tween 20 ), and were homogenized by vortexing until they were completely lysed. Standard reaction solution was prepared according to the manufacturer's instructions and was placed on ice in the dark before use. Before measurement, samples (5 $\mu \mathrm{L}$ ) were added in 96-well plates and equilibrated for $10 \mathrm{~s}$. Subsequently, $200 \mu \mathrm{L}$ standard reaction solution was added into each well and the light signal was integrated for $10 \mathrm{~s}$ after a delay of $2 \mathrm{~s}$. The light intensity in the control group was arbitrarily set as 1 , and that in the treatment group was measured and expressed as relative values with respect to the control group. 


\section{Statistical analysis}

Each experiment was repeated at least three times, and representative images are shown in the figures. The change of protein NO level, GSNOR expression, active mitochondria, and APT level during oocyte aging at 0, 24, and $48 \mathrm{~h}$, as well as caspase 3 expression and ROS production in Fresh, Aging $24 \mathrm{~h}$, and Aging $24 \mathrm{~h}+$ SNP were subjected to the multivariate analysis of variance (ANOVA), and differences among treatments were examined using the Duncan multiple range test. Other data were subjected to the Student's $t$-test. All percentage data were subjected to arcsine transformation prior to statistical analysis and then presented as mean \pm SEM. Significance was set at $p$ $<0.05$. All calculations were performed using SPSS software v.19 (SPSS, Inc., Chicago, IL, USA).
A

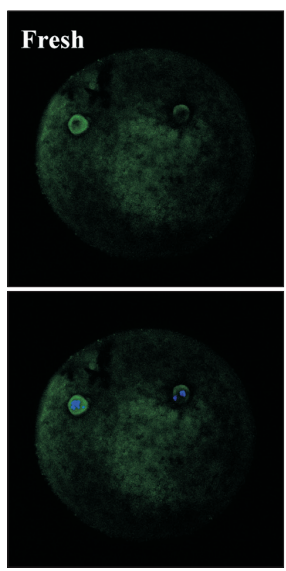

C

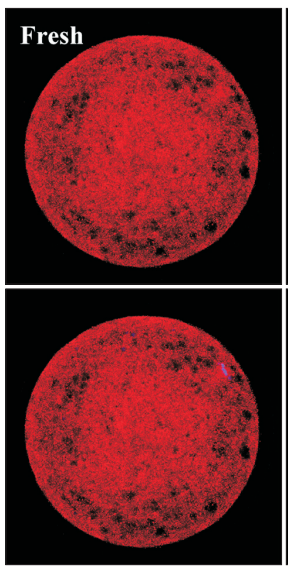

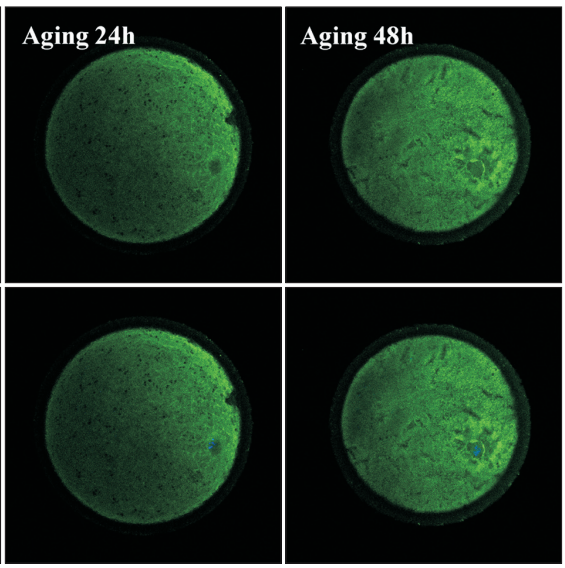

Hoechst/protein SNO level
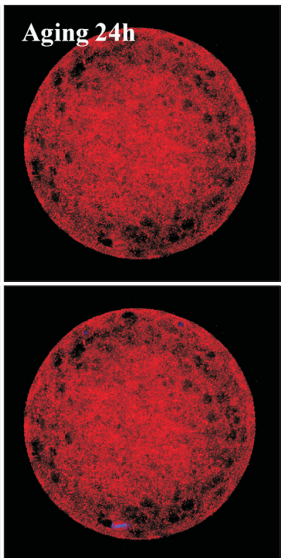

\section{RESULTS}

\section{Protein SNO level and GSNOR expression increases during oocyte aging}

Status of the protein SNO was determined using the Biotin-switch assay. As shown in Fig. 1, the protein SNO level had significantly increased during 24 and $48 \mathrm{~h}$ aging of oocytes as compared to fresh oocytes, while the expression of GSNOR, the main denitrosylation enzyme was not changed after $24 \mathrm{~h}$ of aging. However, the GSNOR expression level increased significantly after $48 \mathrm{~h}$ of aging (Fig. 1B). Thus, markers of both nitrosylation as well as denitrosylation were upregulated in $48 \mathrm{~h}$ of oocyte aging.
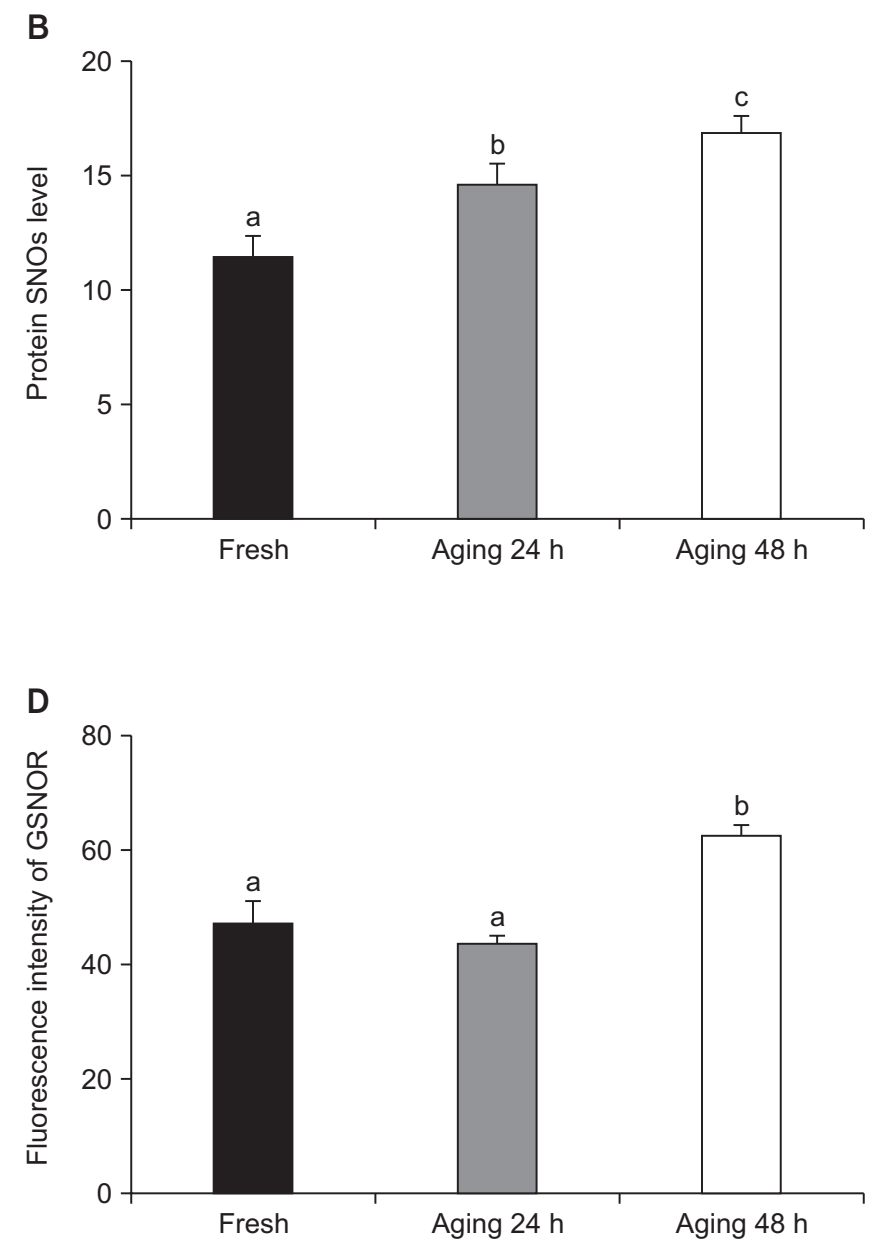

Fig. 1. Protein SNO level and GSNOR expression increases during oocyte aging. Images (A) and protein SNO level (B) of fresh oocytes (n $=15)$, and those aged for $24 \mathrm{~h}(\mathrm{n}=16)$, and $48 \mathrm{~h}(\mathrm{n}=17)$. Images $(C)$ and fluorescence intensity of GSNOR (D) in the fresh oocytes ( $\mathrm{n}$ $=15)$, and those aged for $24 \mathrm{~h}(\mathrm{n}=11)$, and $48 \mathrm{~h}(\mathrm{n}=16)$. Different letters indicate significant difference, $p<0.05$. 


\section{Mitochondrial activity and function decrease during oocyte aging}

To understand the relationship of mitochondrial function with the protein SNO level, active mitochondria were stained with the MitoTracker Red CMXRos at 0, 24, and $48 \mathrm{~h}$ of aging. The results showed that the fluorescence intensity of MitoTracker Red CMXRos decreased after 24 and $48 \mathrm{~h}$ of aging (Fig. 2A and B). Mitochondrial function was measured in terms of amount of ATP with luciferinluciferase ATP assay. As shown in Fig. 2C, ATP level decreased after 24 and $48 \mathrm{~h}$ of aging, suggesting that the mitochondrial function was impaired with oocyte aging.

\section{Treatment with SNP increases protein SNO level and} leads to accumulation of damaged mitochondria

As a NO donor, SNP increases the concentration of NO. Treatment with SNP for $24 \mathrm{~h}$ significantly promoted pro-

A

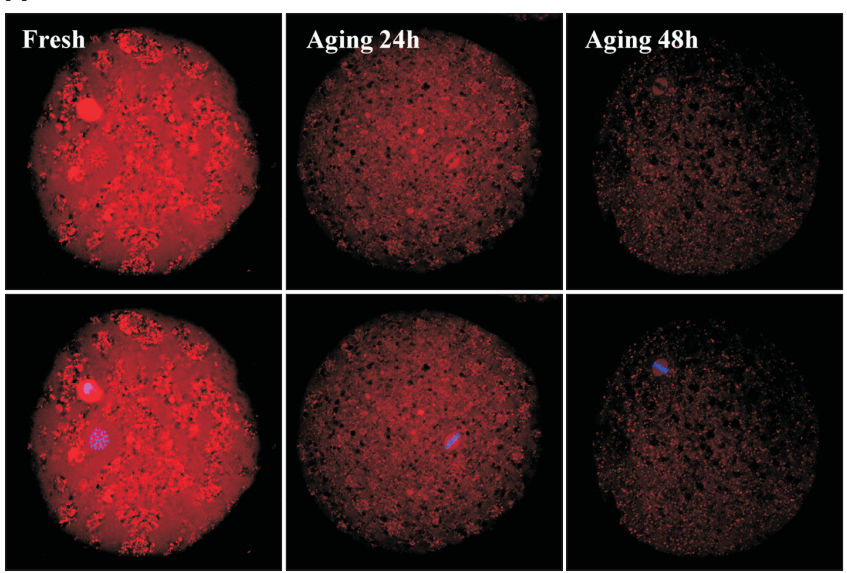

Hoechst/MitoTracker Red CMXRos tein SNO production compared to control oocytes (Fig. 3A and B). This served as a model for oocytes with high NO. As reported previously, total and active mitochondria can be differentially labeled with TOM20 and MitoTracker Red CMXRos (Pendergrass et al., 2004). These labelling experiments showed that the TOM20 signal in SNP-treated oocytes was stronger than that in control, but the MitoTracker Red CMXRos signal in SNP-treated oocytes was weaker than that in controls (Fig. 3C). The fluorescence intensity of TOM20 significantly increased in treated oocytes compared to controls, suggesting the total number of mitochondria increased due to exposure to SNP (Fig. 3D). However, decreased intensity of fluorescence with MitoTracker Red CMXRos in treated oocytes (Fig. 3E), suggested that the number active mitochondria decreased due to SNP-treatment. In addition, the ratio between the fluorescence intensity of MitoTracker Red CMXRos
B

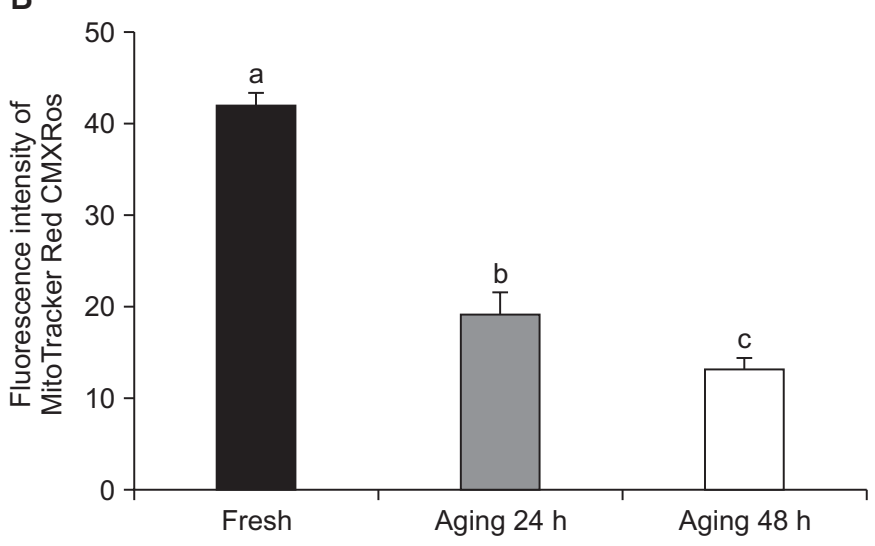

C

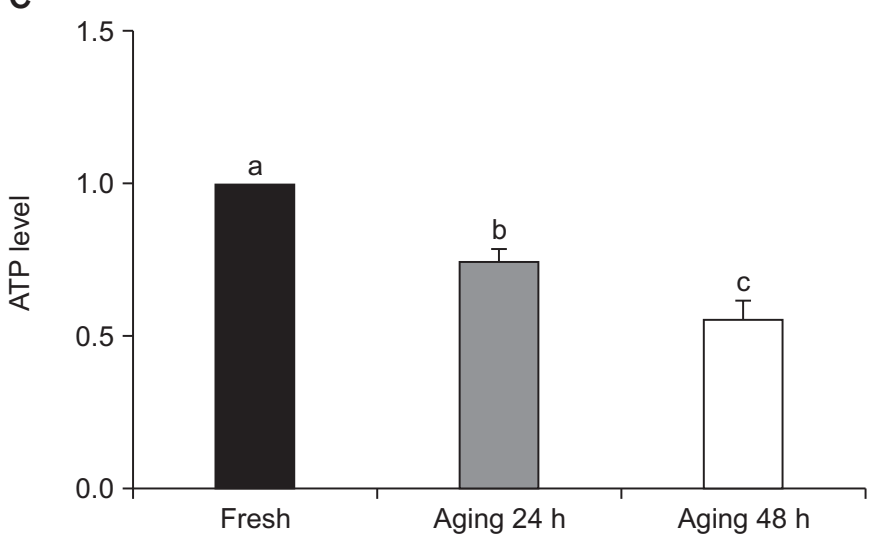

Fig. 2. Mitochondrial activity and function decrease during oocyte aging. Images (A) and fluorescence intensity of MitoTracker Red CMXRos (B) in fresh oocytes ( $n=19)$, and those aged for $24 \mathrm{~h}(\mathrm{n}=13)$, and $48 \mathrm{~h}(\mathrm{n}=11)$. (C) ATP level in the fresh oocytes, and oocytes aged for $24 \mathrm{~h}$ and $48 \mathrm{~h}$. Different letters indicate significant difference, $p<0.05$. 
A

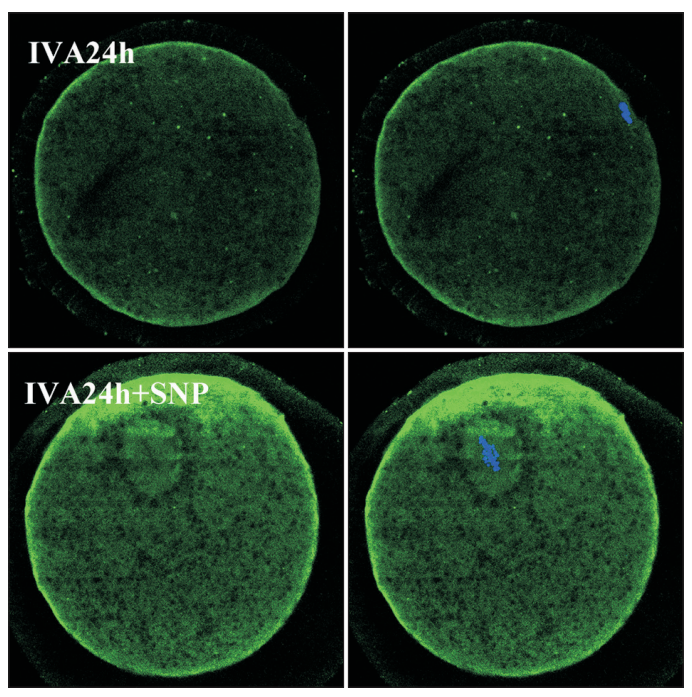

Hoechst/protein SNO level
C
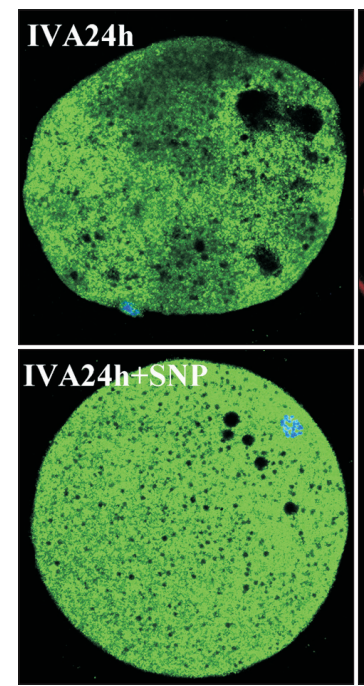

B

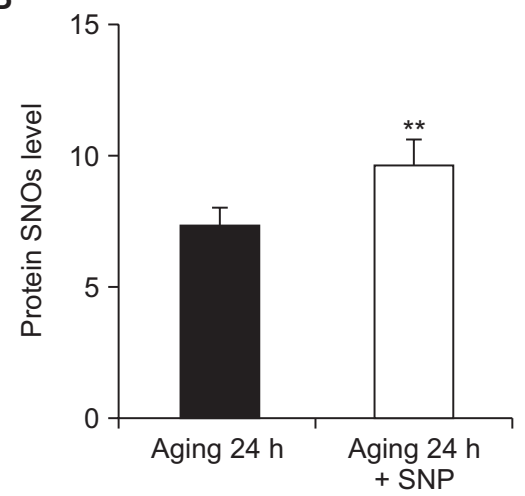

$\mathbf{F}$

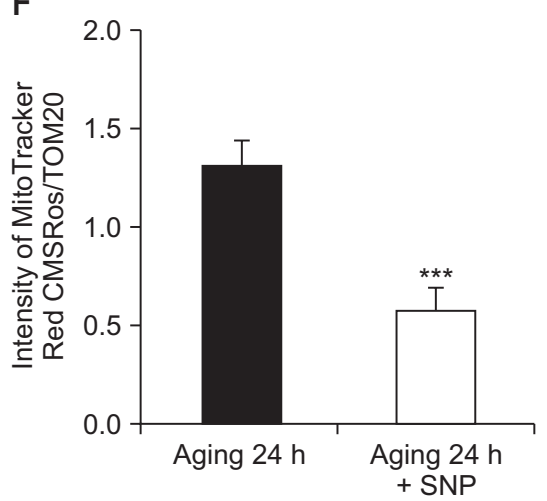

D

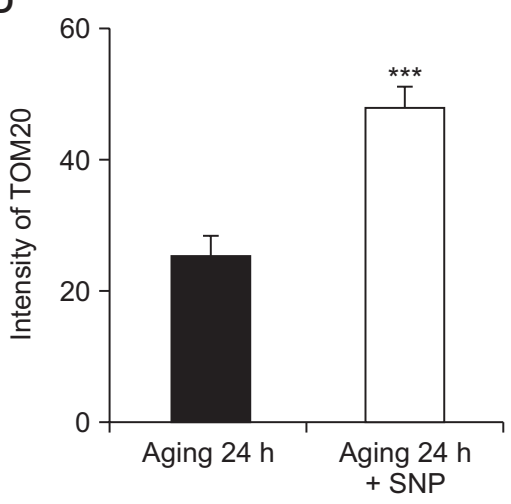

G

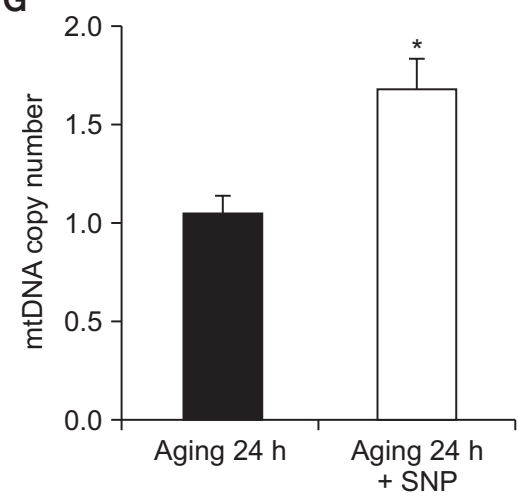

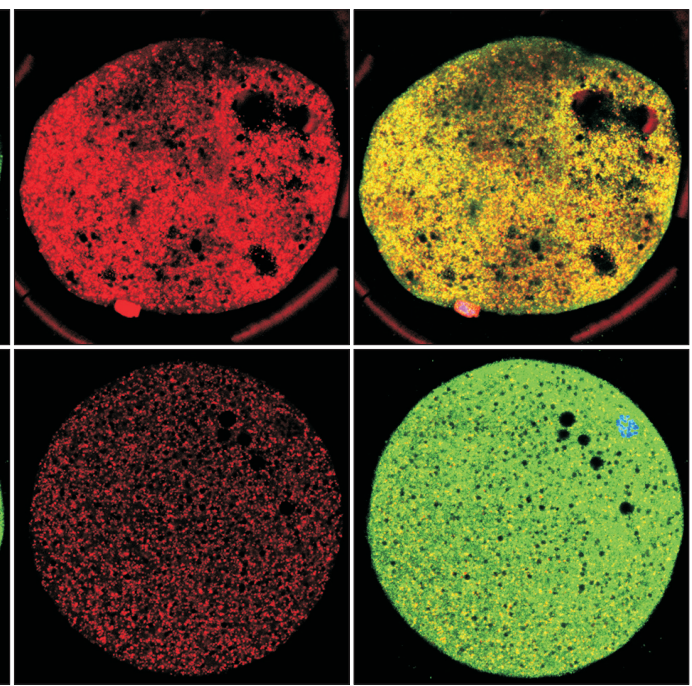

Hoechst/TOM20/MitoTracker Red CMXRos

E

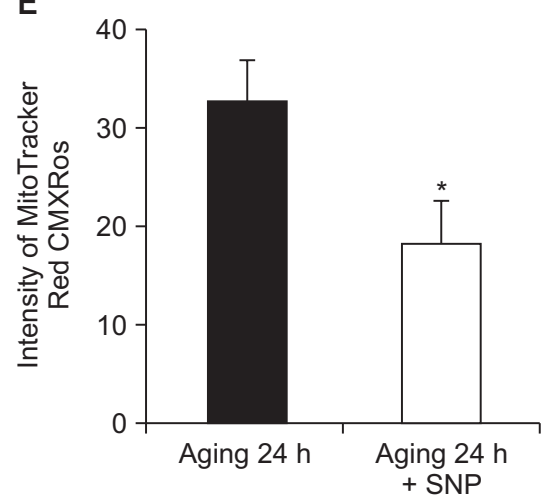

H

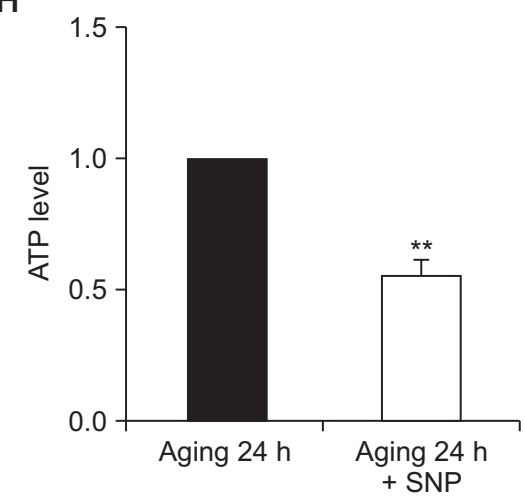

Fig. 3. Treatment with SNP increases protein SNO level and causes accumulation of damaged mitochondria. Images (A) and protein SNO level $(B)$ in the oocytes aged for $24 \mathrm{~h}(\mathrm{n}=14)$ and aged for $24 \mathrm{~h}+$ treated with SNP $(\mathrm{n}=11)$. (C) Colocalization of TOM20 and MitoTracker Red CMXRos in the oocytes aged for $24 \mathrm{~h}(\mathrm{n}=13)$ and aged $24 \mathrm{~h}+$ treated with SNP $(\mathrm{n}=20)$. Fluorescence intensities of TOM20 (D), MitoTracker Red CMXRos (E), and intensity ratio of MitoTracker Red CMXRos/TOM20 (F) in the oocytes aged for 24 $h(n=13)$ and aged for $24 h+$ treated with SNP $(n=20)$ oocytes. (G) MtDNA copy number in oocytes aged for $24 \mathrm{~h}$ and aged for 24 $\mathrm{h}+$ treated with SNP. (H) ATP levels in oocytes aged for $24 \mathrm{~h}$ and aged for $24 \mathrm{~h}+$ treated with SNP. ${ }^{*} p<0.05,{ }^{* *} p<0.01,{ }^{* * *} p<0.001$ versus Aging $24 \mathrm{~h}$. 
and TOM20 was significantly less after SNP-treatment (Fig. 3F). All of these results together suggested that even though the total mitochondrial contents increased due to exposure of oocytes to NO, the proportion of active mitochondria decreased, leading to an accumulation of damaged mitochondria. Mitochondrial DNA copy number as seen on real-time quantitative PCR also showed that SNP-treated oocytes contained more mitochondria after aging for $24 \mathrm{~h}$ in vitro (Fig. 3G). However, the ATP level, estimated using luciferin-luciferase ATP assay system, was reduced in SNP-treated oocytes, indicating a drop in the number of active mitochondria. Taken together, these results imply that increasing NO level caused accumulation of damaged and dysfunctional mitochondria, and reduction of active mitochondria.

A

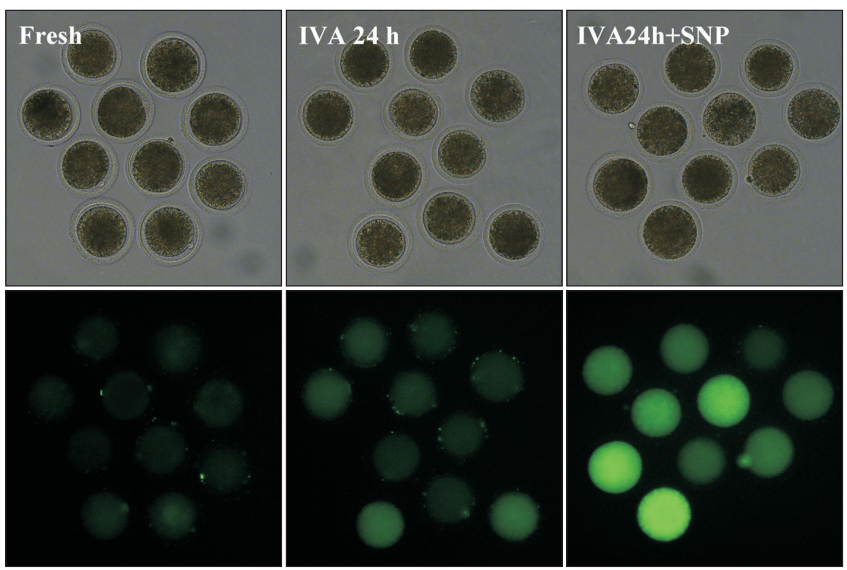

Bright light/ROS

\section{C}
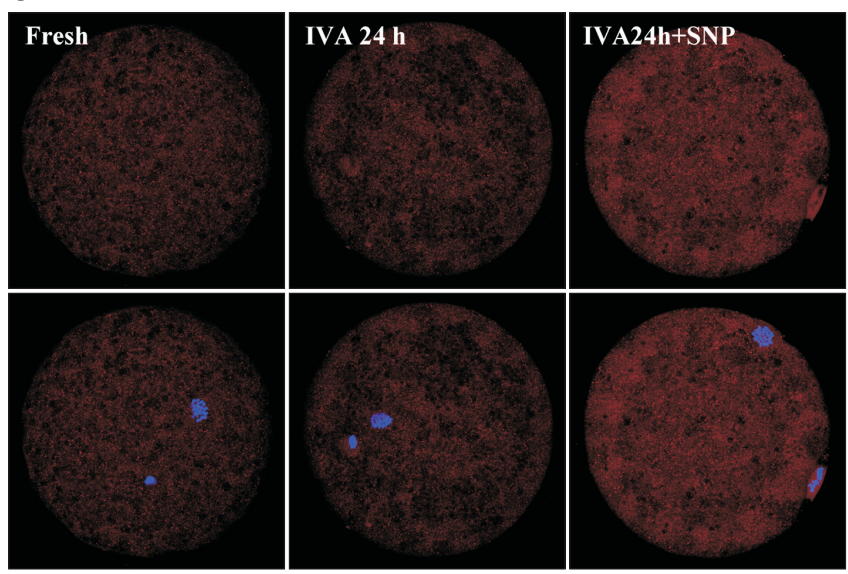

\section{Treatment with SNP increases ROS production and apoptosis level}

To further investigate the effects of increase in NO level on oocyte aging, extent of ROS production and apoptosis were studied. ROS production was determined with $\mathrm{H}_{2}$ DCF-DA staining. As shown in Fig. $4 \mathrm{~A}$ and B, ROS level increased drastically after $24 \mathrm{~h}$ of aging in vitro. Moreover, treatment with SNP further increased the ROS production. Apoptosis was estimated by staining with antiCaspase- 3 antibody. Although aging oocytes for $24 \mathrm{~h}$ alone did not change the level of apoptosis, treatment with SNP significantly increased it, compared to fresh and control oocytes. This suggested that aging for $24 \mathrm{~h}$ may not be enough to cause apoptosis, but further increase in NO level promoted apoptosis.

B

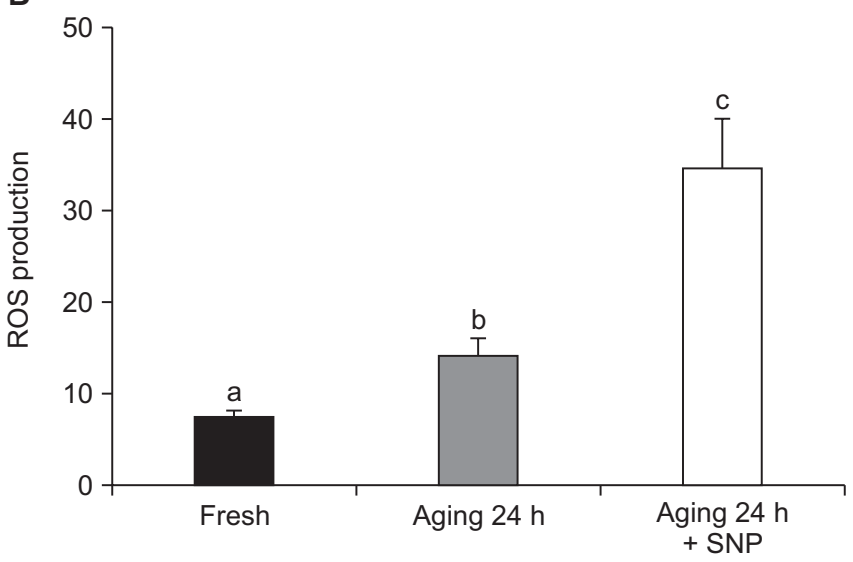

D

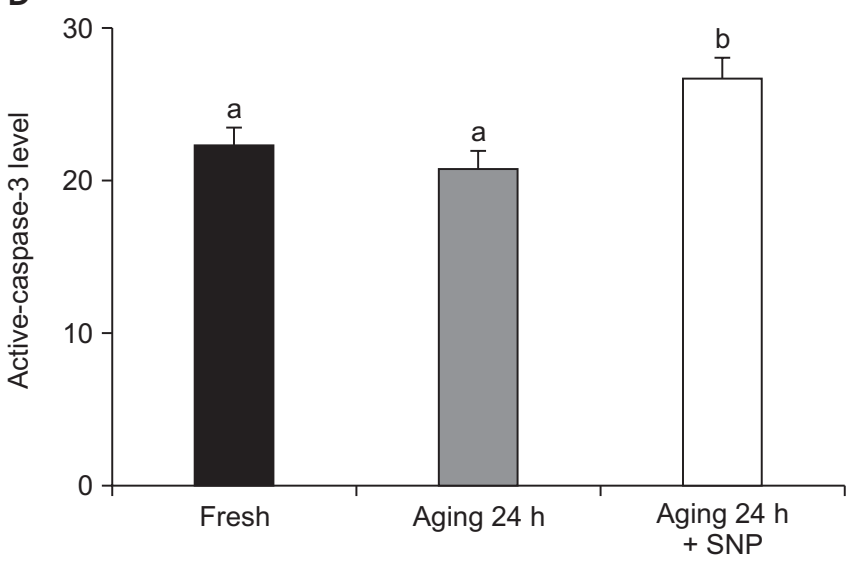

Fig. 4. Treatment with SNP increases ROS production and apoptosis level. Images (A) and ROS production (B) in the fresh oocytes $(n=10)$, and those aged for $24 \mathrm{~h}(\mathrm{n}=10)$, and aged for $24 \mathrm{~h}+$ treated with SNP $(\mathrm{n}=10)$. Images $(C)$ and apoptosis level (D) in the fresh oocytes $(n=10)$, those aged for $24 \mathrm{~h}(\mathrm{n}=11)$, and aged for $24 \mathrm{~h}+$ treated with SNP $(\mathrm{n}=10)$. Different letters indicate significant difference, $p<0.05$. 


\section{DISCUSSION}

Poor quality of oocytes, resulting from environmental pollution and advanced maternal age, has led to failure in conception, requiring assisted reproduction technology (ART) to help to conceive. Since 1978, many children have been born through ART. However, the efficiency of ART needs to be improved for its wider use. One of the main reasons for failure of ART is because of the extra time needed for the in vitro operation, which increases the time the mature oocytes are held in vitro, leading to oocyte aging. If the aging of the oocytes can be prevented, or at least, slowed down, fertilizable period of the oocyte can be extended. Previous studies have shown that the addition of antioxidants can reduce ROS levels, thereby delay the oocyte aging to some extent (Liu et al., 2012; Lord and Aitken, 2013; Li and Cui, 2016; Wang et al., 2017; Liang et al., 2018; Wang et al., 2019; Zhang et al., 2019), but this was not found to be sufficiently effective for clinical use. During the oocyte aging, the redox balance is disrupted, and the oxidative pressure triggers a series of events that ultimately reduce the quality of oocytes. It also induces mitochondrial dysfunction, leading to apoptosis (Tatone et al., 2011; Zhang et al., 2011; Lord et al., 2013), and oxidative damage to the cell (Guérin et al., 2001). Consequence of all these events are reflected in the lower rate of fertilization and poor quality of embryo, increasing the likelihood of abnormalities in the resultant offspring.

A previous study had reported that nitric oxide (NO) signals mediate the aging of oocytes (Premkumar and Chaube, 2015). However, very limited research has addressed the effects of NO-related redox signaling on oocyte quality during oocyte aging. To investigate the role of NO signals in oocyte aging, we studied several aspects of normal oocytes, including mitochondrial functions and contents, ROS production, and apoptosis. The results indicated a close correlation between NO signals and oocyte aging. Treatment with SNP significantly increased the protein SNO level, oxidative stress and mitochondrial dysfunction, accumulation of damaged mitochondria, and apoptosis.

NO-related redox signaling induces s-nitrosylation of proteins, affects morphology and function of mitochondria, increases the release of stored calcium from the endoplasmic reticulum, and affects autophagy and apop- tosis (Sun et al., 2007). Mitochondria are essential for the normal development of oocytes, and mitochondrial quality control is an important protective step to ensure the steady state of mitochondria. Normally, damaged mitochondria are cleared by mitophagy, ensuring that only healthy mitochondria are present in the cells. In addition, mitochondrial biogenesis supports this process. However, when the quality control of mitochondria is weakened, damaged mitochondria start accumulating. In this study, after $24 \mathrm{~h}$ aging, SNP-treated oocytes contained more mitochondria, but the number of active mitochondria significantly reduced, indicating that the proportion of inactive mitochondria was increasing in these oocytes. In these oocytes, the damaged mitochondria were not cleared probably because their mitochondrial quality control system was faulty. The main reason for this effect may be due to S-nitrosylation of PINK1 and Parkin, components of the mitochondrial quality control system, which impairs their function and inhibits mitophagy. Due to the limited number of oocytes, it is difficult to determine the S-nitrosylation status of PINK1 and Parkin, but the increase in the number of damaged mitochondria is clearly seen.

The conclusion of this study is that during the oocyte aging process, the NO level increased, and it affected the quality control system of the mitochondria, particularly the mitophagy, resulting in the accumulation of damaged mitochondria, and production of ROS. Our results provide clues for new ways to delay oocyte aging. While preventing oxidative stress in oocytes, ensuring the steady state of NO signals will ultimately increase the efficiency of ART by delaying oocyte aging.

\section{CONFLICTS OF INTEREST}

No potential conflict of interest relevant to this article was reported.

\section{ACKNOWLEDGEMENTS}

This work was supported by the National Research Foundation (NRF) of Korea grant funded by the Korea government (ministry of education science and technology) (No. 2018R1A2B6001173), and during the research year of Chungbuk National University in 2019. 


\section{AUTHOR CONTRIBUTIONS}

Xiang-Shun Cui, Ying-Jie Niu designed the experiment. Ying-Jie Niu conducted the experiments, analyzed the results, and wrote the article. Dongjie Zhou, Wenjun Zhou, Zheng-Wen Nie and Ju-Yeon Kim helped with the analyses of the results and figures. YoungJin Oh and SoRim Lee conducted some of the experiments. Xiang-Shun Cui assisted in the analyses of the results and revised the manuscript.

\section{AUTHOR'S POSITION AND ORCID NO.}

\author{
YJ Niu, Post-Doc., \\ https://orcid.org/0000-0003-1829-1718 \\ D Zhou, PhD Student, \\ https://orcid.org/0000-0002-4065-0732 \\ W Zhou, PhD Student, \\ https://orcid.org/0000-0002-7329-8149 \\ ZW Nie, PhD Student, \\ https://orcid.org/0000-0002-7353-7963 \\ JY Kim, MS Student, \\ https://orcid.org/0000-0003-3538-2830 \\ YJ Oh, Researcher, \\ https://orcid.org/0000-0003-0438-3873 \\ SR Lee, Researcher, \\ https://orcid.org/0000-0001-9227-8373 \\ XS Cui, Professor, \\ https://orcid.org/0000-0001-6180-6401
}

\section{REFERENCES}

Choi BH, Park BY, Kong R, Son MJ, Park CS, Shin NH, Cheon HY, Yang YR, Lee JW, Jin JI, Kong IK. 2019. Effect of serum and serum free media on the developmental competence of OPU derived bovine IVP embryo. J. Anim. Reprod. Biotechnol. 34:305-310.

Choudhury SM, Bhuiyan MMU, Rahman MM, Rahman MM, Sharif MN, Bhattacharjee J, Bari FY, Juyena NS. 2017. Comparison between two cryo-devices for vitrification of immature oocytes of indigenous zebu cows in Bangladesh. J. Emb. Trans. 32:311-317.

Dodson MG, Minhas BS, Curtis SK, Palmer TV, Robertson JL. 1989. Spontaneous zona reaction in the mouse as a limiting factor for the time in which an oocyte may be fertilized. J. In Vitro Fert. Embryo Transf. 6:101-106.

Ducibella T, Duffy P, Reindollar R, Su B. 1990. Changes in the distribution of mouse oocyte cortical granules and ability to undergo the cortical reaction during gonadotropin-stim- ulated meiotic maturation and aging in vivo. Biol. Reprod. 43:870-876.

Fang X, Qamar AY, Yoon KY, Cho J. 2018. Improved preimplantation development of porcine cloned embryos by flavone supplement as antioxidant. J. Emb. Trans. 33:255-264.

Guérin P, El Mouatassim S, Ménézo Y. 2001. Oxidative stress and protection against reactive oxygen species in the preimplantation embryo and its surroundings. Hum. Reprod. Update 7:175-189.

Hassan BMS, Fang X, Roy PK, Shin ST, Cho JK. 2017. Effect of alpha lipoic acid as an antioxidant supplement during in $\mathrm{Vi}$ tro maturation medium on bovine embryonic development. J. Emb. Trans. 32:123-130.

Haun F, Nakamura T, Shiu AD, Cho DH, Tsunemi T, Holland EA, La Spada AR, Lipton SA. 2013. S-nitrosylation of dynamin-related protein 1 mediates mutant huntingtin-induced mitochondrial fragmentation and neuronal injury in Huntington's disease. Antioxid. Redox Signal. 19:1173-1184.

Hess DT and Stamler JS. 2012. Regulation by S-nitrosylation of protein post-translational modification. J. Biol. Chem. 287:4411-4418.

Hwang IS, Kwon DJ, Kwak TU, Lee JY, Hyung NW, Yang H, Oh KB, Ock SA, Park EW, Im GS, Hwang S. 2016. Effect of a short-term in vitro exposure time on the production of in vitro produced piglets. J. Emb. Trans. 31:117-121.

Iyer AK, Rojanasakul Y, Azad N. 2014. Nitrosothiol signaling and protein nitrosation in cell death. Nitric Oxide. 42:9-18.

Jaffrey SR, Erdjument-Bromage H, Ferris CD, Tempst P, Snyder SH. 2001. Protein S-nitrosylation: a physiological signal for neuronal nitric oxide. Nat. Cell Biol. 3:193-197.

Jeon YE, Hwangbo Y, Cheong HT, Park CK. 2019. Effects of hyaluronidase during in vitro maturation on maturation and developmental competence in porcine oocytes. J. Anim. Reprod. Biotechnol. 34:86-92.

Kikuchi K, Naito K, Noguchi J, Kaneko H, Tojo H. 2002. Maturation/M-phase promoting factor regulates aging of porcine oocytes matured in vitro. Cloning Stem Cells 4:211-222.

Kim SY, Lin T, Lee JB, Lee JE, Shin HY, Jin DI. 2019. Expression pattern of early transcription factors in porcine oocytes and embryos. J. Anim. Reprod. Biotechnol. 34:123-129.

Lee HJ, Park BJ, Jeon RH, Jang SJ, Son YB, Lee SL, Rho GJ, Kim SJ, Lee WJ. 2019a. Alteration of apoptosis during differentiation in human dental pulp-derived mesenchymal stem cell. J. Anim. Reprod. Biotechnol. 34:2-9.

Lee SY, Park CJ, Nam YK. 2019b. Assessment of suitable reference genes for RT-qPCR normalization with developmental samples in pacific abalone Haliotis discus hannai. J. Anim. Reprod. Biotechnol. 34:280-291.

Lee TH, Lee MS, Huang CC, Tsao HM, Lin PM, Ho HN, Shew JY, Yang YS. 2013. Nitric oxide modulates mitochondrial activity and apoptosis through protein S-nitrosylation for preimplantation embryo development. J. Assist. Reprod. Genet. 30:1063-1072.

Li Q and Cui LB. 2016. Combined inhibitory effects of low temperature and $\mathrm{N}$-acetyl-1-cysteine on the postovulatory aging 
of mouse oocytes. Zygote 24:195-205.

Liang QX, Lin YH, Zhang CH, Sun HM, Zhou L, Schatten H, Sun QY, Qian WP. 2018. Resveratrol increases resistance of mouse oocytes to postovulatory aging in vivo. Aging (Albany NY) 10:1586-1596.

Liu J, Liu M, Ye X, Liu K, Huang J, Wang L, Ji G, Liu N, Tang X, Baltz JM, Keefe DL, Liu L. 2012. Delay in oocyte aging in mice by the antioxidant N-acetyl-L-cysteine (NAC). Hum. Reprod. 27:1411-1420.

Lord T and Aitken RJ. 2013. Oxidative stress and ageing of the post-ovulatory oocyte. Reproduction 146:R217-R227.

Lord T, Nixon B, Jones KT, Aitken RJ. 2013. Melatonin prevents postovulatory oocyte aging in the mouse and extends the window for optimal fertilization in vitro. Biol. Reprod. 88:67.

Nakamura T and Lipton SA. 2011. Redox modulation by S-nitrosylation contributes to protein misfolding, mitochondrial dynamics, and neuronal synaptic damage in neurodegenerative diseases. Cell Death Differ. 18:1478-1486.

Nasr-Esfahani MH, Aitken JR, Johnson MH. 1990. Hydrogen peroxide levels in mouse oocytes and early cleavage stage embryos developed in vitro or in vivo. Development 109:501-507.

Park SH, Jeon Y, Yu IJ. 2017. Effects of antioxidants supplement in porcine sperm freezing on in vitro fertilization and the glutathione and reactive oxygen species level of presumptive zygotes. J. Emb. Trans. 32:337-342.

Pendergrass W, Wolf N, Poot M. 2004. Efficacy of MitoTracker Green $^{\mathrm{TM}}$ and CMXRosamine to measure changes in mitochondrial membrane potentials in living cells and tissues. Cytometry A 61:162-169.

Premkumar KV and Chaube SK. 2015. Nitric oxide signals postovulatory aging-induced abortive spontaneous egg activation in rats. Redox Rep. 20:184-192.

Raju K, Doulias PT, Evans P, Krizman EN, Jackson JG, Horyn O, Daikhin Y, Nissim I, Yudkoff M, Nissim I, Sharp KA, Robinson MB, Ischiropoulos H. 2015. Regulation of brain glutamate metabolism by nitric oxide and S-nitrosylation. Sci. Signal. 8:ra68.

Rizza S, Cardaci S, Montagna C, Di Giacomo G, De Zio D, Bordi M, Maiani E, Campello S, Borreca A, Puca AA, Stamler JS, Cecconi F, Filomeni G. 2018. S-nitrosylation drives cell se- nescence and aging in mammals by controlling mitochondrial dynamics and mitophagy. Proc. Natl. Acad. Sci. U. S. A. 115:E3388-E3397.

Seth D, Hess DT, Hausladen A, Wang L, Wang YJ, Stamler JS. 2018. A multiplex enzymatic machinery for cellular protein S-nitrosylation. Mol. Cell 69:451-464.e456.

Sun J, Morgan M, Shen RF, Steenbergen C, Murphy E. 2007. Preconditioning results in S-nitrosylation of proteins involved in regulation of mitochondrial energetics and calcium transport. Circ. Res. 101:1155-1163.

Tatone C, Di Emidio G, Barbaro R, Vento M, Ciriminna R, Artini PG. 2011. Effects of reproductive aging and postovulatory aging on the maintenance of biological competence after oocyte vitrification: insights from the mouse model. Theriogenology 76:864-873.

Wakayama S, Thuan NV, Kishigami S, Ohta H, Mizutani E, Hikichi T, Miyake M, Wakayama T. 2004. Production of offspring from one-day-old oocytes stored at room temperature. J. Reprod. Dev. 50:627-637.

Wang T, Gao YY, Chen L, Nie ZW, Cheng W, Liu X, Schatten H, Zhang X, Miao YL. 2017. Melatonin prevents postovulatory oocyte aging and promotes subsequent embryonic development in the pig. Aging (Albany NY) 9:1552-1564.

Wang Y, Li L, Fan LH, Jing Y, Li J, Ouyang YC, Wang ZB, Hou Y, Sun QY. 2019. N-acetyl-L-cysteine (NAC) delays post-ovulatory oocyte aging in mouse. Aging (Albany NY) 11:20202030.

Xu Z, Abbott A, Kopf GS, Schultz RM, Ducibella T. 1997. Spontaneous activation of ovulated mouse eggs: time-dependent effects on M-phase exit, cortical granule exocytosis, maternal messenger ribonucleic acid recruitment, and inositol 1,4,5-trisphosphate sensitivity. Biol. Reprod. 57:743-750.

Zhang M, ShiYang X, Zhang Y, Miao Y, Chen Y, Cui Z, Xiong B. 2019. Coenzyme Q10 ameliorates the quality of postovulatory aged oocytes by suppressing DNA damage and apoptosis. Free Radic. Biol. Med. 143:84-94.

Zhang N, Wakai T, Fissore RA. 2011. Caffeine alleviates the deterioration of $\mathrm{Ca}(2+)$ release mechanisms and fragmentation of in vitro-aged mouse eggs. Mol. Reprod. Dev. 78:684701 . 